\title{
PARTHENOLIDE REDUCES GENE TRANSCRIPTION OF PROSURVIVAL MEDIATORS IN U937 CELLS
}

\author{
S. Mohammadi ${ }^{1}$, M. Zahedpanah ${ }^{2, *}$, M. Nikbakht ${ }^{1}$, M. Shaiegan ${ }^{3}$, S. Hamidollah Ghaffari ${ }^{1}$, \\ M. Nikugoftar ${ }^{3}$, B. Rahmani, D. Hamedi Asl ${ }^{4}$ \\ ${ }^{1}$ Hematology, Oncology and Stem Cell Transplantation Research Center, Tehran University of Medical \\ Sciences, Tehran 14176-13151, Iran \\ ${ }^{2}$ Department of Medical Laboratory Sciences, Faculty of Allied Medicine, Qazvin University of Medical \\ Sciences, Qazvin 34157-38477, Iran \\ ${ }^{3}$ Blood Transfusion Research Center, High Institute for Research and Education in Transfusion Medicine, \\ Tehran 14665-1157, Iran \\ ${ }^{4}$ Department of Biochemistry and Genetics, Qazvin University of Medical Sciences, Qazvin 34157-38477, Iran
}

In acute myeloid leukemia (AML) the functional abnormalities of osteopontin (OPN), NF-kB, PI3K/AKT/mTOR/PTEN pathway or $\beta$-catenin have been considered. Aim: To analyze the response of U937 cells to parthenolide (PTL) through the involvement of expression of OPN protein, RelB, AKT1, mTOR, PTEN and $\beta$-catenin genes. Materials and Methods: The U937 cells were treated with PTL at concentrations of $4 \mu \mathrm{M}$ (IC25) or $6 \mu \mathrm{M}$ (IC50) and with OPN siRNA for MTT assay and colony forming assay. Western blot analysis using antibodies against OPN was performed with lysates of PTL-treated cells. Quantitative real-time polymerase chain reaction was performed using primers for OPN siRNA, RelB, AKT1, mTOR, PTEN and $\beta$-catenin. Results: PTL reduces OPN protein level and down-regulates RelB mRNA in U937 cell line. Suppression of OPN with siRNA increases the cytotoxic effects of PTL. Also, mRNA expression of AKT1, mTOR, PTEN, and $\beta$-catenin decreases with PTL or OPN siRNA. Conclusion: Sensitivity of U937 cells to PTL can be associated with the reduction in expression of prosurvival mediators.

Key Words: parthenolide, osteopontin, ReIB, AKT1, mTOR, $\beta$-catenin, U937 cells.

The varying response of acute myeloid leukemia $(A M L)$ cells to apoptosis-inducing agents reflects the heterogeneous biological nature of AML [1]. Generally, an apoptosis evasion can be achieved by activating anti-apoptotic molecules. Phosphoinositide 3-kinases (PI3Ks) regulate a variety of important cellular functions, such as growth, cell cycle progression, apoptosis. Human leukemic cells display abnormal regulation of crucial factor in PI3Ks pathway, which will be useful to interpret the mechanisms of resistance to the conventional class of chemotherapeutic agents [2].

The functional abnormalities of osteopontin (OPN), nuclear factor-kB (NF-kB), PI3K/AKT/mTOR/PTEN pathway or $\beta$-catenin have been considered as the crucial factors in drug resistance [2-5].

OPN is a glycoprotein expressed by cells in a variety of tissues, including hematopoietic cells [6, 7]. The OPN transcript has been detected in metastatic cancer cell line [8]. The increased serum level of OPN in AML cells could be used as a prognostic marker [3] .

NF-kB is a protein complex including RelA/p65 and RelB that controls transcription, cytokine production and cell survival [9]. In the alternative (or noncanonical) NF-kB pathway, NF-kB2 p100/RelB complexes are inactive in the cytoplasm [10]. RelA induces RelB gene transcription and mediates the stimuli-driven increase in RelB transcription [11]. RelB by a motif unique among the NF-KB family, leucine zipper motif, could

Submitted: August 22, 2016.

*Correspondence: E-mail: zhdpnh@yahoo.com Abbreviations used: AML - acute myeloid leukemia; OPN - osteopontin; PI3K- phosphoinositide 3-kinase; PTL - parthenolide. have an extra link with various DNA sequences [12] and a number of physiologic responses [13].

The role of RelB in the promotion of tumor cell survival and correlation with high expression level of antiapoptotic NF-kB target genes in multiple myeloma has been reported [14]. The expression of RelB mRNA and protein in monocytes, macrophages, and neutrophils is inducible [11].

The PI3K/AKT/mTOR pathway is an important intracellular signaling pathway regulating the cellular quiescence and proliferation. The molecules of this pathway are constitutively activated in many types of cancer [15].

$\beta$-catenin protein is imported into the nucleus and activates transcription of target genes including cyclin D1 and c-MYC. Aberrant activation of the Wnt/ $\beta$ catenin pathway contributes to carcinogenesis and malignant behavior, and Wnt signaling is essential for the maintenance of cancer stem cells [16]. In addition, genetic inactivation of PTEN also leads to constitutive activation of the PI3K/AKT/mTOR axis $[2,17]$.

Knowledge of alternative therapies realizing their functional characteristics may provide new approaches to sensitize malignant cells. Therefore, considering functions of the above mentioned mediators involved in malignancies, an alternative therapy such as parthenolide (PTL) targeting the expression of these molecule may be useful as an effective treatment for AML.

PTL is a natural sesquiterpene lacton from Tanacetum parthenium (feverfew). PTL can interact with nucleophilic sites on biological macromolecules. Studies on this extract have suggested that it induces apop- 
tosis in leukemic cells [18-20]. PTL exerts apoptosis, inhibition of cell proliferation or antitumor activity either through NF-kB inhibition and/or possibly by other mechanisms $[20,21]$ including activation suppression of Akt and mTOR [22], blocking of STAT3 activity [23] and increase in reactive oxygen species [24].

In the present study, we tried to analyze the response of myelomonocytic leukemic U937 cells [25] to PTL through expression of cytoprotective mediator OPN protein, RelB, AKT1, mTOR, PTEN and $\beta$-catenin genes. In addition, we examined whether inhibition of OPN mRNA can affect the viability, proliferation, and transcription of the above-mentioned pro-survival genes in U937 cells.

\section{MATERIALS AND METHODS}

Reagents. PTL purchased from Sigma-Aldrich (Sigma-Aldrich, St. Louis, MO) was dissolved in dimethyl sulfoxide (DMSO) as a $50 \mathrm{mM}$ stock solution, stored at $-20^{\circ} \mathrm{C}$ and diluted in the distilled water prior to use. The IgG2a mouse anti-human OPN and mouse anti-human $\beta$-actin monoclonal antibodies, as well as the horseradish peroxidase-conjugated secondary goat anti-mouse IgG antibody were purchased from R\&D Systems (R\&D System, Minneapolis, MN). TriPure isolation Reagent was purchased from Roche Applied Science (Penzberg, Germany). The cDNA synthesis kit and SYBR ${ }^{\circledR}$ Premix Ex Taq $^{\mathrm{TM}}$ were purchased from Takara Biotechnology Co (Otsu, Japan).

Cell culture. The human myelomonocytic leukemic U937 cell line was obtained from the Pasteur Institute of Iran and cultured in RPMI 1640 with $10 \%$ FBS (Gibco, Carlsbad, CA). The medium were supplemented with $2 \mathrm{mM} \mathrm{L-glutamine,} 100$ units/ml penicillin and $100 \mu \mathrm{g} / \mathrm{ml}$ streptomycin. Cells were incubated at $37^{\circ} \mathrm{C}$ in a humidified atmosphere containing $5 \% \mathrm{CO}_{2}$.

MTT assays. U937 cells were cultured in triplicate at $5 \cdot 10^{3} / 100 \mu \mathrm{l}$ in 96 -well culture plates (SPL Life sciences, Pocheon, Korea). The cells were treated with different concentrations of PTL based on determined $\mathrm{IC}_{25}$ or $\mathrm{IC}_{50}$ in our previous study [26]. After incubation $\left(37^{\circ} \mathrm{C}, 5 \% \mathrm{CO}_{2}\right)$, the cells were incubated for $4 \mathrm{~h}$ with 3-(4,5-dimethylthiazol-2-yl)-2,5-diphenyltetrazolium bromide (MTT, $5 \mathrm{mg} / \mathrm{ml}$ ) (Sigma-Aldrich, St. Louis, $\mathrm{MO})$. The plates were spun, and the purple formazan crystals of yellow tetrazolium salt metabolized by viable cells were dissolved in DMSO. Absorbance was quantified at $570 \mathrm{~nm}$ using the ELISA plate reader (Microplate Reader; Bio-Rad, USA). Results were expressed as a percentage of viability, with $100 \%$ representing control cells treated with $0.1 \% \mathrm{DMSO}$ alone.

Colony forming assay. U937 cells were suspended at a density of 2000 cells in $0.5 \mathrm{ml}$ of RPMI 1640 , and then treated with PTL alone or simultaneously in combination with OPN siRNA. The treated and untreated cell line were plated in Methocult semisolid media (Stem Cell Technologies, Vancouver, BC, Canada). After 14-16 days incubation, the colonies were enumerated by inverted microscope. Accumulation of $\geqslant 50$ cells was scored as granulocyte-macrophage colony-forming units and collection of 3-50 cells was considered as one cluster. Three independent experiments were performed.

Western blotting analysis. The cells $\left(1 \cdot 10^{6} \mathrm{cells} / \mathrm{ml}\right)$ were incubated with $4 \mu \mathrm{mol} / \mathrm{l}$ PTL for $24 \mathrm{~h}$. Then cells were lysed in the lysis buffer containing 1.0\% Nonidet P-40, $150 \mathrm{mM} \mathrm{NaCl}, 20 \mathrm{mM}$ Tris- $\mathrm{HCl}$ (pH 7.5), $5 \mathrm{mM}$ EDTA, and a protease inhibitor mixture tablet Complete (Roche Diagnostics, Indianapolis, IN). Extracted proteins $(60 \mu \mathrm{g})$ were loaded on SDS-PAGE and transferred on PVDV Membrane (Roche). After that the membranes were blocked by skimmed milk (Merck) and immunoblotted with mouse anti-human OPN and mouse anti-human $\beta$-actin antibodies. Membranes were visualized using an appropriate horseradish peroxidase-conjugated secondary antibody and enhanced chemiluminescenceWestern blotting detection system (Roche Diagnostics, Indianapolis, IN).

Quantitative real-time polymerase chain reaction (qRT-PCR). Total RNA of the PTL-treated and untreated cell line was extracted with TriPure isolation reagent according to the manufacturer's instruction. The cDNA synthesis kit was used for complementary DNA (cDNA) synthesis. A light cycler instrument (Roche Diagnostic, Manheim, Germany) and SYBR Premix Ex Taq were used for quantitative real-time analysis. A final volume of $20 \mu \mathrm{l}$ containing $2 \mu \mathrm{l}$ of a 2 -fold diluted cDNA, $1 \mu \mathrm{l}$ of $10 \mathrm{pmol}$ primers $(0.5 \mu \mathrm{l}$ each forward and reverse primers), $10 \mu \mathrm{l}$ of SYBER and $7 \mu \mathrm{l}$ distilled water were used. Data were normalized to HPRT expression in each sample. Analysis of relative gene expression data were performed using the $2^{-\Delta c t}$ method. The Table shows the primer sequences for genes used.

Table. The primers used in qRT-PCR

\begin{tabular}{llr}
\hline \multicolumn{1}{c}{ Gene } & Forward primer $\left(5^{\prime}-3^{\prime}\right)$ & Reverse primer $\left(5^{\prime}-3^{\prime}\right)$ \\
\hline HPRT & TGGACAGGACTGACGTCTTG & CCAGCAGGTCAGCAAAGATTTA \\
OPN & ACCCTTCCAAGTAAGCCAACG & GGTGAGATCATCAGTGTCATCTAC \\
NF-B/ReIB & GCCTGACTITGAGGGACTGTA & CTAGATGCAAGGCTGTTCGTC \\
AKT1 & AGCGACGTGGCTATTGTGAAG & GTACTCCCCTCGTTTTGCAG \\
mTOR & AACTCCGAGAGATGAGTCAAGA AGTTGGTCATAGAAGCGAGTAGA \\
PTEN & TGGATTCGACTTAGACTTGACCT TTTGGCGGTGTCATAATGTCTT \\
$\beta$-Catenin & TACCTCCCAAGTCCTGTATGAG & TGAGCAGCATCAAACTGTGTAG \\
\hline
\end{tabular}

RNA interfering. The siRNA against OPN was applied to PTL-treated cells using lipofectamin 2000 reagent (LF2000; $10 \mu \mathrm{g} / \mathrm{ml}$; Invitrogen), according to the manufacturer's instruction. Cells were lysed $24 \mathrm{~h}$ posttransfection and quantitative real-time RT-PCR was performed using following sequences of OPN siRNA primers: 5'-CCAAGUAAGUCCAACGAAA (dTdT)-3' (sense) and 5'-UUUCGUUGGACUUACUUGG (dTdT)$3^{\prime}$ (anti-sense). Highest transfection efficiency with minimal effects on cell viability was obtained in optimization experiments within $24 \mathrm{~h}$ post-transfection at a final concentration $40 \mathrm{pmol} / \mathrm{ml}$ and we used these optimal conditions for subsequent experiments with test siRNAs.

Statistical analysis. Using IBM SPSS Statistics 19 software the groups of data were presented as means \pm SD and compared by one-way analysis of variance (ANOVA). 


\section{RESULTS}

PTL reduces OPN protein in $U 937$ cells. To determine the effects of PTL on transcriptional activity of OPN as a putative cell resistance factors in response to chemotherapy, we investigated protein levels of OPN by Western blotting analysis. The results showed that PTL at concentration of $4 \mu \mathrm{M}\left(\mathrm{IC}_{25}\right.$ value for U937) can reduce OPN protein in U937 cells (Fig. 1). This confirms our previous study in which OPN mRNA levels decrease was shown by qRT-PCR [26].

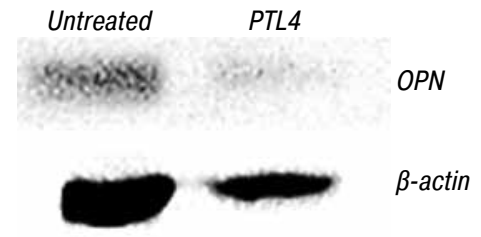

Fig. 1. Western blotting analysis shows decrease in OPN protein level in PTL-treated U937 cells

PTL decreases NF-kB/ReIB mRNA expression in $U 937$ cells. NF- $k B / R e l B$ gene expression was significantly attenuated in PTL-treated U937 cells (Fig. 2). This finding implies a concurrence between OPN and NF-kB/RelB expression. In the other words, PTL might reduce the expression of both $O P N$ and NF-kB/RelB either by separate mechanisms or in some way related to each other.

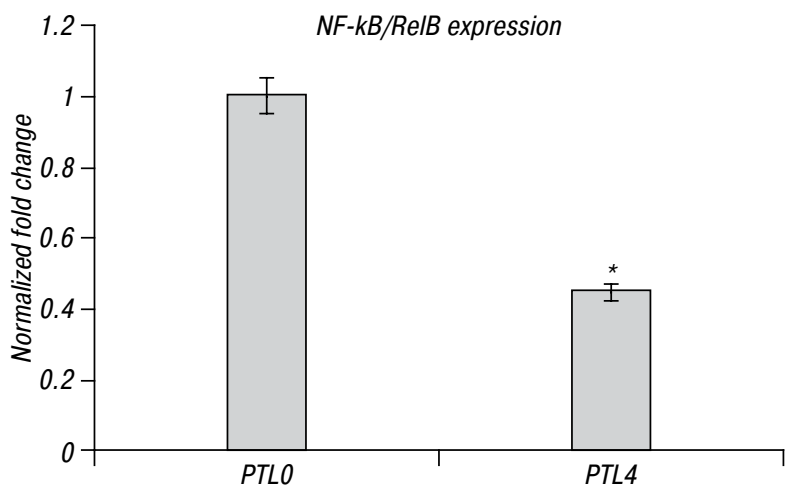

Fig. 2. $P T L$ treatment decreases NF-kB/RelB expression in U937 cells. Evaluation of mRNA expression of OPN relative to HPRT, using RT-PCR after treatment of U937 cells with PTL for $24 \mathrm{~h}$. Three independent experiments were performed (mean \pm SD). ${ }^{*} p<0.05$

Suppression of OPN with siRNA increases the cytotoxic effects of PTL on U937 cells. To investigate whether the OPN gene knockdown decreases the cell viability and proliferation after PTL addition, we used optimized OPN siRNA. The PTL treatment subsequently after OPN siRNA addition decreased the cell viability and clonogenic growth compared with the control (without siRNA and PTL treatment) in U937 cells (Fig. 3). These observations imply that OPN plays an important role in the regulation of survival and proliferation of AML cells.

PTL and OPN SIRNA decreases the MRNA expression of AKT, mTOR, PTEN, and $\beta$-catenin. To investigate the further involvement of the OPN expression concerned with PTL effects on expression of some crucial mediators, which are necessary toward cell proliferation and survival (i.e. AKT1, mTOR, $\beta$-catenin and PTEN), we examined the effects of OPN suppression by siRNA on transcription of those genes. Either
OPN siRNA or PTLalone or co-treatment of OPN siRNA with PTL in comparison with non-treatment control reduced the expression of those molecules in U937 cells. It suggests that OPN may play a role in controlling the expression of those genes. Given that OPN siRNA reduces expression of all four genes to near-undetectable levels, it could be deduced that PTL failed to impact overall gene expression (Fig. 4).
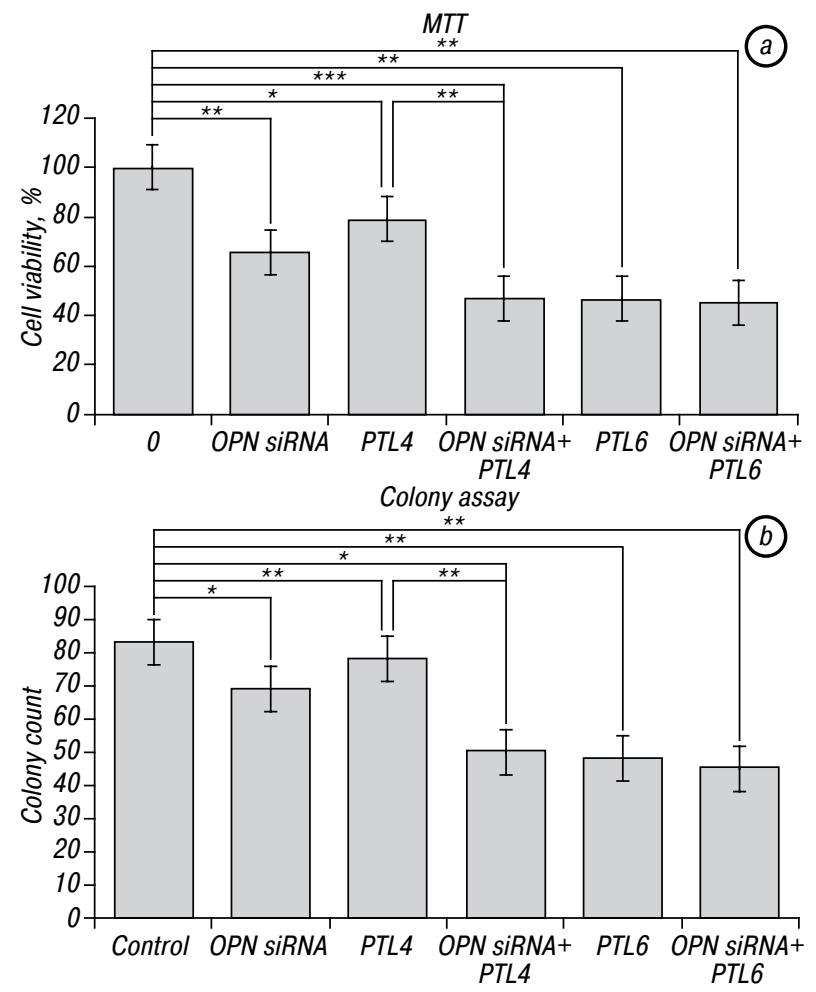

Fig. 3. Suppression of OPN with siRNA increases the cytotoxic effects of PTL on U937 cells. Transfection of U937 cells with OPN siRNA or treatment with PTL displayed a decrease in (a) the viability percent and $(b)$ the colony formation count compared with untreated cells. Three independent experiments were performed (mean $\pm \mathrm{SD}$ ). ${ }^{*} p<0.05,{ }^{* \star} p<0.01,{ }^{* \star \star} p<0.001$ (compared with control)

\section{DISCUSSION}

In our previous work concerning PTL effect on OPN gene expression in U937 cells we were faced with OPN reduction [26]. The present study showed that OPN is also attenuated in protein levels in PTL-treated U937 cells. We found that suppression of OPN with siRNA decreased the viability and colony-forming ability of U937 cells in presence of PTL.

When a malignant cell resists to chemotherapeutic agents, the relapse and failure in treatment can occur [27]. Several relatively recent studies have pointed to PTL as a novel antileukemic agent that can selectively eliminate LSCs and progenitor cells [19, 20]. Nonetheless some mediators bestow a resistance to apoptosis advantage upon the PTL-treated cells [28]. The effects of high expression of OPN on leukemogenesis and cell protection from cytotoxic agents have been presented [29]. Besides, the studies on HL-60 cells give evidence that leukemia cells may produce OPN mRNA [8, 30]. Therefore, OPN might be involved in the PTL effects in some hematopoietic malignancies. 

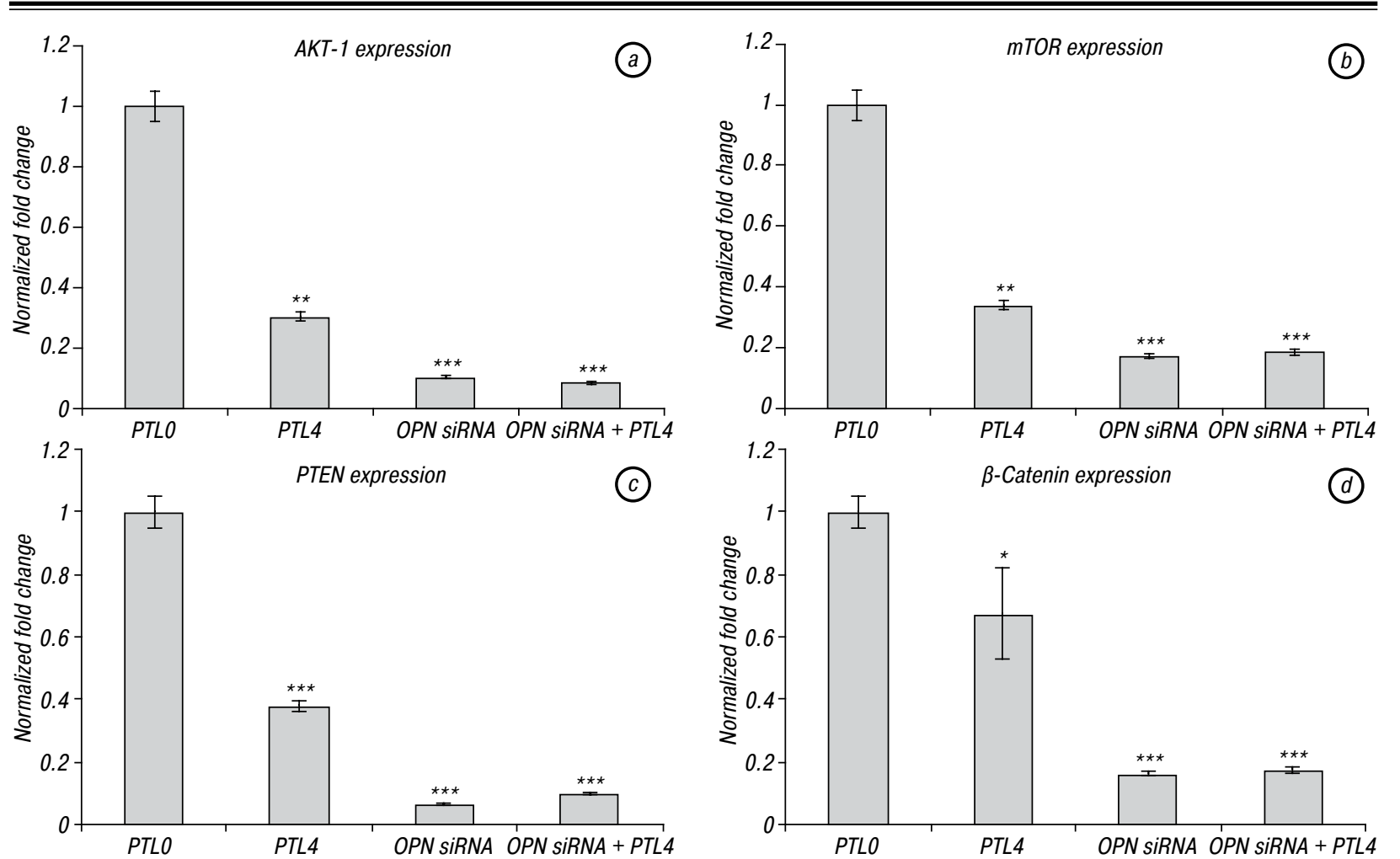

Fig. 4. PTL and OPN siRNA decrease the mRNA expression of AKT, mTOR, $\beta$-catenin or PTEN. The effects of OPN suppression by siRNA on transcription of $A K T 1$, mTOR, $\beta$-catenin and PTEN genes, relative to HPRT, were analyzed by quantitive RT-PCR. Three independent experiments were performed (mean $\pm \mathrm{SD}$ ). ${ }^{\star} p<0.05,{ }^{\star \star} p<0.01,{ }^{\star \star \star} p<0.001$ (compared with control)

We found that the vulnerability of U937 cells to PTL increases when OPN gene expression is inhibited. The reductive effect of PTL on OPN expression in U937 cells could be attributable to inhibition of transcription factor AP-1 as known OPN transcriptional activator, alike what has been reported in cystic fibrosis [31]. In addition, the proapoptotic potency of PTL in cancer cells is expressed interfering directly or indirectly with crucial proteins that function as gene transcriptional regulatory units, especially with NF-kB $[32,33]$. In our work, PTL could be involved in the gene transcription of $N F-k B / R e / B$ consistent with OPN gene expression mode in U937 cells. There is a number of reports of a NF$\mathrm{kB}$ binding site on OPN promoter and the mutual relation between OPN expression and NF-kB activation [34-37].

PTL can induce apoptosis in leukemic cells through additional mechanisms such as PI3K pathway suppression, induction of reactive oxygen species, and activation of stress response proteins [22, 24, 38-40]. We also observed that PTL decreased the MRNA levels of $A K T$, mTOR, $\beta$-catenin and PTEN in U937 cells. These genes are oncogenes or tumor suppressor genes that have important role in the control of the cell cycle or apoptosis and they are frequently activated or suppressed in AML [41]. The suppressing effect of PTL on AKT/mTOR activation in malignancies has been already reported [22, 38, 42, 43]. According to UCSC genome browser on human, there are several binding sites of NF-kB in the AKT and PTEN promoter region that might have been intervened in PTL effects. The interferential role of the transcription factors that may be common for these mediators (STAT3 as an example) could exert subtractive effects of PTL on their transcription. There is an AP- 1 binding site in AKT promoter region and with regard to afore-mentioned this suggests a possible route toward $A K T$ transcriptional inhibition by PTL $[31,44-46]$. There is an evidence of the inhibitory effect of PTL on the ERK pathway, which in turn activates proto-oncogenic transcription factor TCF employing $\beta$-catenin to induce gene expression [31, 47]. Given that PTEN is an opponent for AKT/mTOR and subsequently for $\beta$-catenin as well as OPN, the levels of its expression might be coincided with them as seen in association of the activation of Akt and OPN with the PTEN activation [48]. The aberrant transcripts of PTEN in U937 have been reported [49], then the lower viability in PTL-treated U937 cells could be attributed to PTEN deficiency the same as in PTENdeficient myeloma cells being more sensitive to mTOR inhibition with accompanying reduction in viability [50].

In view of the more pronounced reduction of the above mentioned mRNA levels in cells transfected with OPN siRNA in comparison with untreated or PTL-exposed cells, it seems that OPN plays a role in the mechanisms of the transcription of these genes. To our knowledge, no other investigation has been conducted in association between OPN and transcriptional regulation of our studied genes. However, the role of OPN in activation of the intracellular PI3K/Akt signal pathway following binding to avß3 integrin or CD44 has been described [51-53]. Also, there is a report that OPN induces mTOR phosphorylation at Ser-2448 [37]. Besides, an overall increase in $\beta$-catenin protein levels with a resultant transfer of $\beta$-catenin to the nucleus subsequent to OPN-induced Akt activation has been suggested [54]. There are others reports implying OPN participation in transcription of vari- 
ous genes that can be exerted by multiple pathways including PI3K/AKT, Wnt- $\beta$-catenin, P70S6K/mTOR, and IKBa/IKK $[37,54,55]$.

In summary, the sensitivity of U937 cells to PTL can be associated with the reduced expression of prosurvival mediators such as OPN, AKT1, mTOR or $\beta$-catenin.

\section{ACKNOWLEDGMENT}

All authors claim no conflicts of interest or financial involvements with this manuscript. This study was funded by Blood Transfusion Research Center, High Institute for Research and Education in Transfusion Medicine and by Hematology, Oncology and Stem Cell Transplantation Research Center, Shariati Hospital.

\section{REFERENCES}

1. O'Donnell MR, Abboud CN, Altman J, et al. Acute myeloid leukemia. J Natl Compr Canc Netw 2012; 10: 984-1021.

2. Mohammadi S, Ghaffari SH, Shaiegan M, et al. Acquired expression of osteopontin selectively promotes enrichment of leukemia stem cells through AKT/mTOR/PTEN/ beta-catenin pathways in AML cells. Life Sci 2016; 152: 190-8.

3. Liersch R, Gerss J, Schliemann C, et al. Osteopontin is a prognostic factor for survival of acute myeloid leukemia patients. Blood 2012; 119: 5215-20.

4. Baumgartner B, Weber M, Quirling M, et al. Increased IkB kinase activity is associated with activated NF-kB in acute myeloid blasts. Leukemia 2002; 16: 2062-71.

5. Wang Y, Krivtsov AV, Sinha AU, et al. The Wnt/ $\beta$ catenin pathway is required for the development of leukemia stem cells in AML. Science 2010; 327: 1650-3.

6. Weber GF. The metastasis gene osteopontin: a candidate target for cancer therapy. BBA Rev Cancer 2001; 1552: 61-85.

7. Gilliland DG. Molecular genetics of human leukemias: new insights into therapy. In Semin Hematol 2002; 39: 6-11.

8. Liu Y-N, Kang B-B, Chen JH. Transcriptional regulation of human osteopontin promoter by $\mathrm{C} / \mathrm{EBP} \alpha$ and AML-1 in metastatic cancer cells. Oncogene 2004; 23: 278-88.

9. Gilmore TD. Introduction to NF-kB: players, pathways, perspectives. Oncogene 2006; 25: 6680-4.

10. Shao-Cong S. The noncanonical NF-kB pathway. Immunol Rev 2012; 246: 125-40.

11. Bren GD, Solan NJ, Miyoshi H, et al. Transcription of the RelB gene is regulated by NF-kB. Oncogene 2001; 20: 7722-33.

12. Moorthy AK, Huang D-B, Wang VY-F, et al. X-ray structure of a NF-kB p50/RelB/DNA complex reveals assembly of multiple dimers on tandem $\mathrm{kB}$ sites. J Mol Biol 2007; 373: 723-34.

13. Millet $P$, McCall C, Yoza B. RelB: an outlier in leukocyte biology. J Leuk Biol 2013; 94: 941-51.

14. Cormier F, Monjanel H, Fabre C, et al. Frequent engagement of RelB activation is critical for cell survival in multiple myeloma. PLoS One 2013; 8: e59127.

15. King D, Yeomanson D, Bryant HE. PI3King the lock: targeting the PI3K/Akt/mTOR pathway as a novel therapeutic strategy in neuroblastoma. J Pediat Hematol Oncol 2015; 37: 245-51.

16. Ashihara E, Takada T, Maekawa T. Targeting the canonical Wnt/ $\beta$-catenin pathway in hematological malignancies. Cancer Sci 2015; 106: 665-71.

17. Stambolic V, Suzuki A, De La Pompa JL, et al. Negative regulation of PKB/Akt-dependent cell survival by the tumor suppressor PTEN. Cell 1998; 95: 29-39.

18. Guzman ML, Rossi RM, Karnischky L, et al. The sesquiterpene lactone parthenolide induces apoptosis of hu- man acute myelogenous leukemia stem and progenitor cells. Blood 2005; 105: 4163-9.

19. Guzman ML, Rossi RM, Neelakantan S, et al. An orally bioavailable parthenolide analog selectively eradicates acute myelogenous leukemia stem and progenitor cells. Blood 2007; 110: 4427-35.

20. Neelakantan S, Nasim S, Guzman ML, et al. Aminoparthenolides as novel anti-leukemic agents: Discovery of the NF-kB inhibitor, DMAPT (LC-1). Bioorg Med Chem Lett 2009; 19: 4346-9.

21. Hassane DC, Guzman ML, Corbett C, et al. Discovery of agents that eradicate leukemia stem cells using an in silico screen of public gene expression data. Blood 2008; 111: 5654-62.

22. Nam YJ, Lee DH, Lee MS, Lee CS. Sesquiterpene lactone parthenolide attenuates production of inflammatory mediators by suppressing the Toll-like receptor-4-mediated activation of the Akt, mTOR, and NF-kappaB pathways. Naunyn Schmiedebergs Arch Pharmacol 2015; 388: 921-30.

23. Sobota R, Szwed M, Kasza A, et al. Parthenolide inhibits activation of signal transducers and activators of transcription (STATs) induced by cytokines of the IL-6 family. Biochem Biophys Res Commun 2000; 267: 329-33.

24. Wen J, You K-R, Lee S-Y, et al. Oxidative stressmediated apoptosis the anticancer effect of the sesquiterpene lactone parthenolide. J Biol Chem 2002; 277: 38954-64.

25. Harris P, Ralph P. Human leukemic models of myelomonocytic development: a review of the HL-60 and U937 cell lines. J Leukoc Biol 1985; 37: 407-22.

26. Zahedpanah M, Shaiegan M, Ghaffari SH, et al. Parthenolide induces apoptosis in committed progenitor AML cell line U937 via reduction in osteopontin. Rep Biochem Mol Biol 2016; 4: 82-8.

27. Deng $\mathrm{C}-\mathrm{H}$, Zhang Q-P. Leukemia stem cells in drug resistance and metastasis. Chinese Med J 2010; 123: 954-60.

28. Yeo AT, Porco JA, Gilmore TD. Bcl-X L, but not Bcl-2, can protect human B-lymphoma cell lines from parthenolide-induced apoptosis. Cancer Lett 2012; 318: 53-60.

29. Sodek J, Ganss B, McKee MD. Osteopontin. Crit Rev Oral Biol Med 2000; 11: 279-303.

30. Berry JE, Somerman MJ, Khalkhali-Ellis Z, et al. HL-60 cell differentiation and osteopontin expression. Ann N Y Acad Sci 1995; 760: 302-4.

31. Saadane A, Eastman J, Berger M, Bonfield TL. Parthenolide inhibits ERK and AP-1 which are dysregulated and contribute to excessive IL-8 expression and secretion in cystic fibrosis cells. J Inflamm (Lond) 2011; 8: 26.

32. Pajak B, Gajkowska B, Orzechowski A. Molecular basis of parthenolide-dependent proapoptotic activity in cancer cells. Folia Histochem Cytobiol 2008; 46: 129-35.

33. Aggarwal BB, Sethi G, Nair A, Ichikawa H. Nuclear factor-B: a Holy Grail in cancer prevention and therapy. Curr Signal Transduc Ther 2006; 1: 25-52.

34. Zhao W, Wang L, Zhang M, et al. NF-kB- and AP1-mediated DNA looping regulates osteopontin transcription in endotoxin-stimulated murine macrophages. J Immunol 2011; 186: 3173-9.

35. Samant RS, Clark DW, Fillmore RA, et al. Breast cancer metastasis suppressor 1 (BRMS1) inhibits osteopontin transcription by abrogating NF-kappaB activation. Mol Cancer 2007; 6: 2007-11.

36. Cao L, Fan X, Jing W, et al. Osteopontin promotes a cancer stem cell-like phenotype in hepatocellular carcinoma cells via an integrin-NF-kB-HIF- $1 \alpha$ pathway. Oncotarget 2015; 6: 6627-40.

37. Ahmed M, Kundu GC. Osteopontin selectively regulates $\mathrm{p} 70 \mathrm{~S} 6 \mathrm{~K} / \mathrm{mTOR}$ phosphorylation leading to NF-kappaB 
dependent AP-1-mediated ICAM-1 expression in breast cancer cells. Mol Cancer 2010; 9: 101.

38. Nakabayashi H, Shimizu K. Involvement of Akt/NFkappaB pathway in antitumor effects of parthenolide on glioblastoma cells in vitro and in vivo. BMC Cancer 2012; 12: 453.

39. Zunino SJ, Storms DH, Ducore JM. Parthenolide treatment activates stress signaling proteins in high-risk acute lymphoblastic leukemia cells with chromosomal translocation $\mathrm{t}(4 ; 11)$. Int J Oncol 2010; 37: 1307-13.

40. Kim YR, Eom JI, Kim SJ, et al. Myeloperoxidase expression as a potential determinant of parthenolide-induced apoptosis in leukemia bulk and leukemia stem cells. J Pharmacol Exp Ther 2010; 335: 389-400.

41. Park $S$, Chapuis $N$, Tamburini $J$, et al. Role of the PI3K/AKT and mTOR signaling pathways in acute myeloid leukemia. Haematologica 2010; 95: 819-28.

42. Di Fiore R, Drago-Ferrante R, D’Anneo A, et al. In human retinoblastoma $Y 79$ cells okadaic acid-parthenolide co-treatment induces synergistic apoptotic effects, with PTEN as a key player. Cancer Biol Ther 2013; 14: 922-31.

43. Hassane DC, Sen S, Minhajuddin M, et al. Chemical genomic screening reveals synergism between parthenolide and inhibitors of the PI-3 kinase and mTOR pathways. Blood 2010; 116: 5983-90.

44. Kim HJ, Lee MH, Shin HI, et al. Okadaic acid stimulates osteopontin expression through de novo induction of AP-1. J Cell Biochem 2002; 87: 93-102.

45. Dihlmann S, Kloor M, Fallsehr C, von Knebel Doeberitz M. Regulation of AKT1 expression by beta-catenin/Tcf/ Lef signaling in colorectal cancer cells. Carcinogenesis 2005; 26: $1503-12$.

46. Atsaves V, Zhang R, Ruder D, et al. Constitutive control of AKT1 gene expression by JUNB/CJUN in ALK\&plus; anaplastic large-cell lymphoma: a novel crosstalk mechanism. Leukemia 2015; 29: 2162-72.

47. Weber GF. Molecular mechanisms of cancer. Dordrecht: Springer, 2007. 645 p.

48. Sugatani T, Alvarez U, Hruska KA. PTEN regulates RANKL- and osteopontin-stimulated signal transduction during osteoclast differentiation and cell motility. J Biol Chem 2003; 278: 5001-8.

49. Liu TC, Lin PM, Chang JG, et al. Mutation analysis of PTEN/MMAC1 in acute myeloid leukemia. Am J Hematol 2000; 63: 170-5.

50. Shi Y, Gera J, Hu L, et al. Enhanced sensitivity of multiple myeloma cells containing PTEN mutations to CCI-779. Cancer Res 2002; 62: 5027-34.

51. Wang Y, Yan W, Lu X, et al. Overexpression of osteopontin induces angiogenesis of endothelial progenitor cells via the avbeta3/PI3K/AKT/eNOS/NO signaling pathway in glioma cells. Eur J Cell Biol 2011; 90: 642-8.

52. Lin Y-H, Yang-Yen H-F. The osteopontin-CD44 survival signal involves activation of the phosphatidylinositol 3-kinase/Akt signaling pathway. J Biol Chem 2001; 276: 46024-30.

53. Zhang J, Yamada O, Matsushita Y, et al. Transactivation of human osteopontin promoter by human T-cell leukemia virus type 1-encoded Tax protein. Leukemia Res 2010; 34: 763-8.

54. Robertson BW, Chellaiah MA. Osteopontin induces beta-catenin signaling through activation of Akt in prostate cancer cells. Exp Cell Res 2010; 316: 1-11.

55. Philip S, Kundu GC. Osteopontin induces nuclear factor NF-kB-mediated promatrix metalloproteinase-2 activation through $\mathrm{I} x \mathrm{~B} \alpha / \mathrm{IKK}$ signaling pathways, and curcumin (diferulolylmethane) down-regulates these pathways. J Biol Chem 2003; 278: 14487-97. 